\title{
SELF REGULATED LEARNING MAHASISWA PADA PEMBELAJARAN KOOPERATIF STAD DIPADU DENGAN BLENDED LEARNING DALAM MATAKULIAH KIMIA ANALISIS INSTRUMENTASI
}

\section{STUDENTS' SELF REGULATED LEARNING IN STAD COOPERATIVE LEARNING COMBINED WITH BLENDED LEARNING IN INSTRUMENTAL ANALYTICAL CHEMISTRY COURSE}

\author{
Ade Trisnawati \\ Universitas PGRI Madiun, J1. Setiabudi No. 85 Madiun Jawa Timur 63118, Indonesia \\ Email: adetrisnawati14@gmail.com
}

Diterima: 12 Desember 2017. Disetujui: 15 Maret 2018. Dipublikasikan: 31 Maret 2018

\begin{abstract}
Abstrak. Self regulated learning (regulasi diri dalam belajar) merupakan faktor penting dalam pembelajaran online. Kemampuan regulasi diri dalam belajar dibutuhkan mahasiswa agar mampu mengatur dan mengarahkan dirinya sendiri, mampu menyesuaikan dan mengendalikan diri dalam menghadapi tugas-tugas pembelajaran untuk meningkatkan prestasi dalam belajar. Penelitian pra-eksperimental ini bertujuan untuk mendeskripsikan self regulated learning mahasiswa pada pembelajaran kooperatif STAD dipadu dengan blended learning pada matakuliah kimia analisis instrumentasi khususnya pada materi spektroskopi. Sampel penelitian adalah mahasiswa program Pendidikan Kimia Universitas Negeri Malang semester 5 yang berjumlah 34 mahasiswa. Data penelitian didapatkan dari angket self regulated learning mahasiswa dan catatan observer selama penelitian. Hasil penelitian menunjukkan bahwa mahasiswa yang memiliki self regulated learning tinggi lebih banyak (52,94\%) daripada mahasiswa yang memiliki self regulated learning rendah (47,06 \%). Aspek manajemen waktu pada kedua kelompok memiliki skor rata-rata yang tinggi dan indikator pencarian bantuan (help seeking) pada kedua kelompok memiliki skor rata-rata paling rendah.
\end{abstract}

Kata kunci: Pembelajaran kooperatif STAD, Blended learning, Self regulated learning

Abstract. Self regulated learning is an important factor in online learning. Self regulated learning requires students to be able to manage and direct themselves, able to adjust and control themselves in the face of learning tasks to improve achievement in learning. This pre-experimental study aimed to describe the self-regulated learning of students in cooperative learning STAD combined with blended learning in the course of analytical chemistry, especially in the matter spectroscopy instrumentation. Sample of this study were 34 fifth-semester college students majoring at Chemistry studying at State University of Malang. Research data obtained from self-regulated learning questionnaire students and observer records during the study. The results showed that students who have higher self-regulated learning $(52.94 \%)$ than students who have low self-regulated learning $(47.06 \%)$. Time management aspects in both groups had high average scores and help seeking indicators in both groups had the lowest average score.

Keywords: STAD cooperative learning, Blended learning, Self regulated learning

\section{PENDAHULUAN}

Self regulated learning (SRL) adalah kemampuan seseorang untuk mengelola secara efektif pengalaman belajarnya sendiri dalam berbagai cara sehingga mendapat hasil belajar yang optimal [1]. Menurut Pintrich dan Zusho, SRL merupakan proses konstruktif aktif dimana siswa menetapkan tujuan belajarnya. Berusaha untuk memonitor, mengatur, dan mengontrol kognisi, motivasi, dan tingkah lakunya agar sesuai dengan tujuannya dan kondisi kontekstual dari lingkungannya [2]. SRL pada pembelajaran tradisional dalam kaitannya dengan prestasi belajar telah banyak dikaji dan membuktikan bahwa SRL sangat penting dimiliki oleh individu dalam proses pembelajaran. Seseorang yang memiliki SRL, akan cenderung lebih memiliki prestasi atau pemahaman yang baik. Hal ini diperkuat ketika peserta didik memiliki SRL, mereka menetapkan tujuan akademik yang lebih tinggi untuk diri mereka sendiri, belajar lebih efektif dan berprestasi di kelas [3].

Selain dalam pembelajaran tradisional, SRL juga sangat dibutuhkan dalam pembelajaran berbasis online. Pembelajaran kooperatif STAD dipadu dengan blended learning merupakan salah satu pembelajaran yang menyediakan lingkungan belajar dimana mahasiswa bekerja dalam kelompok kecil untuk menyelesaikan pertanyaan atau masalah yang diberikan pengajar yang didukung dengan media online [4-6]. Media online menyediakan ruang bagi mahasiswa untuk berbagi pengalaman dan pengetahuan dengan teman tanpa keterbatasan waktu dan jarak. Beberapa penelitian menyebutkan bahwa SRL merupakan prediktor dari prestasi akademik dalam lingkungan belajar seperti pembelajaran yang berbasis teknologi [7-8]. 
SRL mahasiswa pada lingkungan online mungkin akan lebih penting daripada lingkungan tatap muka karena pada lingkungan online memerlukan tingkatan yang lebih tinggi akan interaksi sesama dan kerjasama, yang membutuhkan lebih proaktif dan pengaturan diri yang terlibat dalam pribadi peserta didik karena kurangnya dukungan dari pengajar [9]. Kemampuan SRL sendiri dibutuhkan mahasiswa agar mampu mengatur dan mengarahkan dirinya sendiri, mampu menyesuaikan dan mengendalikan diri dalam menghadapi tugastugas pembelajaran untuk meningkatkan prestasi dalam belajar. Oleh karena itu, dengan adanya SRL mahasiswa diharapkan lebih bisa menunjukkan usaha yang dapat menunjang keberhasilannya dalam proses belajar. Mahasiswa yang memiliki SRL tinggi akan lebih memilih kegiatan-kegiatan yang dapat menunjang prestasinya. Penelitian ini bertujuan untuk mendeskripsikan SRL mahasiswa pada pembelajaran kooperatif STAD dipadu dengan blended learning pada matakuliah kimia analisis instrumentasi khususnya materi spektroskopi.

\section{METODE PENELITIAN}

Rancangan penelitian yang dilakukan merupakan penelitian pra-eksperimental. Rancangan pra-eksperimental dalam penelitian ini digunakan karena adanya perlakuan untuk mencari pengaruhnya terhadap yang lain dalam satu kelompok subjek [10]. Perlakuan yang dilakukan dalam penelitian ini adalah pembelajaran kooperatif STAD dipadu dengan blended learning pada matakuliah kimia analisis instrumentasi, sedangkan yang ingin diteliti SRL mahasiswa. Dalam studi ini, perpaduan antara pembelajaran kooperatif STAD di kelas dengan pembelajaran online yang dilaksanakan yaitu sebagian langkah pembelajaran pada STAD dilaksanakan pada pembelajaran tatap muka dan sebagian langkah yang lain dilaksanakan pada pembelajaran online [11]. Pada pembelajaran online mahasiswa dapat mengakses media moodle yang berisi materi, video, animasi, tugas, soal-soal, penilaian formatif (kuis) dan melakukan diskusi. Desain pembelajaran ini tidak mengurangi waktu belajar yang dihabiskan mahasiswa di kelas dan penyajian online diharapkan mampu mendorong mahasiswa untuk menjadi aktif dan dapat berkolaborasi dalam menganalisis suatu permasalahan.

Subjek penelitian adalah mahasiswa program studi Pendidikan Kimia Jurusan Kimia Fakultas Matematika dan Ilmu Pengetahuan Alam (FMIPA) Universitas Negeri Malang yang berjumlah 34 mahasiswa yang tergabung dalam satu kelas. Instrumen yang digunakan untuk mengukur SRL mahasiswa adalah angket yang mengadaptasi dari Online Self-regulated Learning Questionnare (OSLQ) yang dikembangkan oleh Barnard et al [12] dimana angket ini mengadapatasi dari instrumen yang dikembangkan Zimmerman tahun 1998. Angket
SRL terdiri dari 30 butir pernyataan (pernyataan negatif dan positif) dengan pilihan berskala 1-4. Aspek dalam angket tersebut terdiri dari enam aspek yaitu menetapkan tujuan (Goal setting), strategi tugas (Task strategis), pengaturan waktu (Time management), evaluasi diri (Self evaluation), penataan lingkungan (Environmental structuring), dan mencari bantuan (Help seeking).

Angket SRL sebelum digunakan dilakukan uji validitas isi dan butir soal angket. Berdasarkan hasil validitas isi angket dari validator secara keseluruhan sebesar 85,75 \% sehingga isi angket termasuk dalam kategori sangat tinggi. Berdasarkan uji item analisis untuk angket SRL diperoleh bahwa sebanyak 28 item butir angket valid dengan probabilitas kurang dari 0,05 . Berdasarkan hasil uji coba dapat diketahui bahwa nilai reliabilitas instrumen angket SRL masing-masing adalah 0,914.

Pengumpulan data diperoleh dari angket self regulated learning yang diberikan kepada mahasiswa pada akhir pembelajaran kooperatif STAD dipadu dengan blended learning kepada mahasiswa dan lembar observasi keterlaksanaan pembelajaran baik pada pembelajaran tatap muka maupun pembelajaran online. Teknik analisis data yang dilakukan adalah menghitung total skor angket yang telah dijawab oleh mahasiswa sesuai dengan item angket dikalikan dengan poinnya menurut skala likert. Mengelompokkan mahasiswa dengan tingkat SRL tinggi dan rendah dengan mencari angka median dari skor SRL mahasiswa. Kemudian menentukan ratarata tiap indikator untuk mahasiswa dengan tingkat SRL tinggi dan rendah.

\section{HASIL DAN PEMBAHASAN}

Data SRL mahasiswa merupakan data hasil angket yang disebarkan pada subyek penelitian setelah akhir proses pembelajaran. Berdasarkan hasil dari penyebaran angket pada mahasiswa, maka data SRL dapat dikelompokkan menjadi kelompok tinggi dan rendah. Pengelompokkan berdasarkan nilai tengah (median) dari data SRL. Berdasarkan statistik deskriptif diperoleh median sebesar 81. Mahasiswa yang mempunyai SRL tinggi yaitu mahasiswa yang mempunyai nilai SRL diatas nilai median sedangkan mahasiswa yang mempunyai SRL rendah yaitu mahasiswa yang mempunyai nilai SRL di bawah nilai median untuk kedua kelompok. Adapun data mengenai SRL dapat dilihat pada Tabel 1 berikut.

Tabel 1. Data Distribusi Self Regulated Learning

\begin{tabular}{ccc}
\hline $\begin{array}{c}\text { Self } \\
\text { Learning }\end{array}$ & \multicolumn{2}{c}{$\begin{array}{c}\text { Metode Kooperatif } \\
\text { berbantuan Moodle }\end{array}$} \\
\cline { 2 - 3 } & Frekuensi (f) & $\begin{array}{l}\text { Persentase } \\
(\boldsymbol{\%})\end{array}$ \\
\hline Tinggi & 18 & 52,94 \\
Rendah & 16 & 47,06 \\
Jumlah & 34 & 100,00 \\
\hline
\end{tabular}


Berdasarkan Tabel 1 dapat diketahui bahwa mahasiswa yang memiliki SRL tinggi adalah 18 mahasiswa dengan persentase 52,94\%, sedangkan yang mempunyai SRL rendah adalah sebanyak 16 mahasiswa dengan persentase 47,06 \%. Dapat diketahui bahwa mahasiswa yang mempunyai SRL tinggi lebih banyak daripada mahasiswa yang memiliki SRL rendah. Data SRL mahasiswa yang diukur meliputi (1) Tujuan (goal setting), (2) struktur lingkungan (environment structuring), (3) Strategi tugas (Task Strategies), (4) Manajemen Waktu (Time Management), (5) Pencarian bantuan (help seeking), (6) Evaluasi diri (self evaluation), (7) Berpikir kritis (critical thinking), (8) Elaborasi (elaboration). Adapun rata-rata skor pada tiap indikator untuk mahasiswa yang memililiki SRL tinggi dan rendah dapat dilihat pada Tabel 2 berikut ini.

Tabel 2. Data Self Regulated Learning Mahasiswa pada Tiap Aspek

\begin{tabular}{llll}
\hline No & $\begin{array}{c}\text { Aspek Self Regulated } \\
\text { Learning }\end{array}$ & $\begin{array}{l}\text { Skor rata-rata } \\
\text { self regulated } \\
\text { learning }\end{array}$ \\
\cline { 3 - 4 } & Tinggi & Rendah \\
\hline 1 & $\begin{array}{l}\text { Tujuan (goal setting) } \\
\text { Struktur lingkungan } \\
\text { (environment }\end{array}$ & 9,61 & 8,50 \\
& 9,44 & 8,13 \\
3 & $\begin{array}{l}\text { structuring) } \\
\text { Strategi tugas (Task } \\
\text { Strategies) }\end{array}$ & 11,50 & 10,13 \\
4 & $\begin{array}{l}\text { Manajemen Waktu } \\
\text { (Time Management) }\end{array}$ & 13,11 & 11,56 \\
5 & $\begin{array}{l}\text { Pencarian bantuan (help } \\
\text { seeking) }\end{array}$ & 9,06 & 8,13 \\
6 & $\begin{array}{l}\text { Evaluasi diri (self } \\
\text { evaluation) }\end{array}$ & 12,56 & 10,50 \\
7 & $\begin{array}{l}\text { Berpikir kritis (critical } \\
\text { thinking) }\end{array}$ & 12,00 & 9,88 \\
8 & Elaborasi (elaboration) & 10,11 & 8,38 \\
\hline
\end{tabular}

Berdasarkan Tabel 2 diperoleh keterangan bahwa data tiap indikator pada mahasiswa yang memiliki SRL tinggi memiliki hasil rata-rata yang lebih tinggi daripada rata-rata pada tiap indikator SRL rendah. Kemudian dapat diketahui pula pada indikator manajemen waktu pada kedua kelompok memiliki skor rata-rata yang tinggi dan indikator pencarian bantuan (help seeking) pada kedua kelompok memiliki skor rata-rata paling rendah.

Pengukuran SRL dalam penelitian ini dilakukan menggunakan rubrik Online Self-regulated Learning Questionnare (OSLQ) yang dikembangkan oleh Barnard et al [12], dimana angket ini mengadaptasi dari instrumen yang dikembangkan Zimmerman tahun 1998. Schunk \& Zimmerman mengemukakan bahwa peserta didik dikatakan melakukan SRL apabila ia secara simultan mengatur perilaku dan kognisinya dengan memperhatikan instruksi, mengontrol berjalannya suatu proses dan mengintegrasikan pengetahuan, melatih untuk mengingat informasi yang diperoleh, serta mengembangkan dan mempertahankan nilai-nilai positif tentang kemampuan belajar mahasiswa [2]. Melalui pembelajaran kooperatif STAD dipadu dengan blended learing menggunakan media moodle diharapkan SRL mahasiswa dapat berkembang karena dalam pembelajaran ini mahasiswa dapat mengatur cara belajarnya sendiri dan menentukan kemampuan belajarnya sesuai dengan apa yang ditargetkannya.

Berpedoman pada hasil analisis deskriptif, diperoleh kesimpulan bahwa mahasiswa yang memiliki SRL tinggi lebih banyak daripada mahasiswa yang memiliki SRL rendah. Begitu pula skor rata-rata pada setiap aspek yang dimiliki mahasiswa dengan SRL tinggi lebih tinggi jika dibandingkan skor rata-rata pada setiap aspek yang dimiliki mahasiswa dengan SRL rendah. Sesuai dengan pendapat Orhan dan Tsai et al yang menyatakan bahwa penggunaan lingkungan belajar yang memadukan antara pembelajaran tatap muka dan pembelajaran online (blended learning) merupakan strategi yang efektif dalam mencoba untuk meningkatkan SRL [13-14]. Seseorang yang mempunyai SRL yang tinggi akan mempunyai hasil belajar yag tinggi pula. Pada waktu seseorang dapat mengoptimalkan kemampuan SRL dengan baik maka pencapaian tujuan yang telah ditetapkan juga dapat dicapai secara optimal. Hasil analisis tersebut didukung oleh hasil angket SRL yang mencakup 8 aspek (faktor) yaitu,

\section{Menetapkan tujuan (Goal setting)}

Menurut Zimmerman, SRL diawali dengan fase perencanaan yang termasuk penetapan tujuan pembelajaran [15]. Menetapkan tujuan ini mengacu pada strategi yang akan digunakan untuk mencapai hasil yang diinginkan. Dalam pembelajaran ini bukti adanya penetapan tujuan tidak diberikan secara gamblang melainkan dapat dilihat pada proses dalam pembelajaran. Strategi belajar agar tercapai tujuan yang dilakukan mahasiswa pada lingkungan pembelajaran berbasis web terlihat pada log harian, koordinasi pada kerja online dan offline dan rencana teknis untuk penyelesaian masalah [16]. Pembelajaran ini menggunakan media pembelajaran moodle dimana dapat diketahui kapan mahasiswa mengunjungi media sehingga dapat diketahui log harian mahasiswa, kapan mereka memulai pembelajaran dan bagaimana percakapan diskusi dalam menyelesaikan suatu masalah. Mahasiswa dengan SRL yang berbeda akan memanfaatkan media pembelajaran moodle sesuai dengan pilihan akan kebutuhan belajar yang mengacu pada tujuan belajar masing-masing.

Berdasarkan data log harian mahasiswa dengan SRL tinggi memiliki frekuensi log yang lebih tinggi daripada mahasiswa dengan SRL rendah. 
Mahasiswa akan mengunjungi moodle untuk membaca percakapan diskusi yang terkait materi yang belum dipahami, mengetahui adanya informasi baru seperti materi baru yang diunggah atau respon mahasiswa dalam diskusi seperti pertanyaan atau informasi yang penting. Analisis hasil transkrip diskusi online menunjukkan bahwa semua mahasiswa memiliki rencana mingguan untuk melengkapi bahan diskusi yang telah diberikan pengajar. Mahasiswa melaporkan bahwa sebelum masuk dalam diskusi online mahasiswa akan menggunakan waktu luang untuk merencanakan apa yang akan dikatakan pada diskusi online sehingga mahasiswa yang lain dapat mengetahui solusi yang diberikan untuk menyelesaikan masalah pada bahan diskusi. Hal-hal tersebut dilakukan karena mahasiswa dengan kemampuan regulasi diri dalam belajar memiliki inisiatif yang kuat untuk menggunakan strategi belajar untuk mencapai tujuan.

\section{Strategi tugas (Task strategis)}

Pembelajaran ini memberikan kebebasan bagi mahasiswa terkait dengan bagaimana strategi yang dilakukan dalam mengerjakan tugas. Pada pembelajaran kooperatif STAD yang dipadu dengan blended learning ini mahasiswa diberikan tugas-tugas yang meliputi tugas pendahuluan yang dikerjakan sebelum pembelajaran tatap muka dimulai, lembar kerja mahasiswa (LKM) dan bahan diskusi online. Untuk melengkapi tugas pendahuluan mahasiswa diminta untuk mengunduh link materi atau video yang akan dirangkum. Berdasarkan hasil analisis dari tugas pendahuluan beberapa mahasiswa memilih untuk membuat tugas pendahuluan berupa peta konsep atau rangkuman singkat. Kemudian isi bahasan dalam rangkuman tidak hanya berasal dari link materi yang diberikan oleh pengajar, mahasiswa mencari link materi lain yang lebih mudah untuk dipahami.

Pada pembelajaran tatap muka, dalam mengerjakan LKM terlebih dahulu mahasiswa akan membaca handout yang dimiliki, membuat catatan singkat, membaca hasil print out link materi yang diberikan pada saat tugas pendahuluan atau mencari sumber informasi pada internet dengan menggunakan alat komunikasi pribadi atau laptop masing-masing. Kemudian untuk menyelesaikan bahan diskusi online mahasiwa diberikan pilihan untuk mencari sumber informasi yang dapat digunakan untuk menyelesaikan bahan diskusi online. Mahasiswa dapat memilih referensi yang disediakan oleh pengajar atau mencari sendiri. Dengan berbagai pilihan tersebut dimungkinkan usaha pengaturan diri mahasiswa meningkat.

\section{Pengaturan waktu (Time management)}

Pengaturan waktu merupakan salah satu kunci dalam proses pengaturan diri, yang mengacu pada pemilihan strategi yang sesuai sehingga dapat membantu untuk mencapai tujuan dan mengatur waktu secara efektif [17]. Dalam penelitian ini alat komunikasi dan kolaborasi yang digunakan yaitu moodle dapat digunakan untuk mendukung proses regulasi diri terkait pengaturan waktu saat melengkapi tugas belajar.

Skor rata-rata pada pengaturan waktu memberikan hasil tertinggi baik pada mahasiswa dengan SRL tinggi dan mahasiswa dengan SRL rendah dengan skor masing-masing 13,11 dan 11,56. Hal ini menunjukkan bahwa mahasiswa berusaha dengan baik untuk mengatur diri terkait pengaturan waktu yang digunakan dalam mempelajari materi spektroskopi pada pembelajaran tatap muka dan pembelajaran online. Berdasarkan hasil observasi mahasiswa selalu menghadiri pembelajaran tatap muka dan pembelajaran online. Dalam pembelajaran online kehadiran mahasiswa dalam media online dapat diketahui pada catatan log harian walaupun ada beberapa yang tidak mengikuti diskusi online. Mahasiswa yang dapat mengatur waktu belajar dengan efisien akan memiliki prestasi yang lebih baik daripada mahasiswa yang tidak dapat mengatur waktu belajar mereka.

Mahasiswa yang memiliki kemampuan SRL mengetahui bagaimana cara mengatur waktu karena mereka waspada terhadap batas akhir dan mengetahui seberapa lama waktu yang digunakan untuk menyelesaikan tugas tersebut [18]. Mahasiswa yang memiliki SRL yang tinggi dalam proses belajar akan memperhitungkan waktu dalam pengerjaan soal dan memperhatikan waktu dalam belajar. Misalnya mahasiswa dengan SRL tinggi akan mengumpulkan tugas-tugas jauh hari sebelum batas waktu pengumpulan sehingga mereka memiliki waktu ekstra untuk mempelajari materi yang dipelajari. Hal ini dilakukan untuk menghindari adanya gangguan pada internet atau gangguan pada komputer yang digunakan.

Dalam penelitian ini waktu yang diberikan untuk diskusi online adalah satu minggu. Mahasiswa dapat mengatur waktu kapan mereka akan berdiskusi dengan kelompok maupun berdiskusi bersama dengan kelompok lainnya. Berdasarkan pola yang diamati mahasiswa akan menggunakan waktu selama tiga hari untuk mencari solusi terkait bahan diskusi yang diberikan kemudian akan berdiskusi dengan kelompok. Kemudian setelah forum diskusi kelas dimunculkan mahasiswa dari tiap kelompok akan memulai untuk memberikan pendapat hasil diskusi kelompok. Mahasiswa dapat menggunakan waktu secara maksimal untuk menyatakan pendapat, memberikan sanggahan, tambahan dan pertanyaan terkait materi yang sedang dibahas.

\section{Evaluasi diri (Self evaluation)}

Evaluasi diri mengindikasikan penilaian mahasiswa terhadap kualitas atau kemajuan dari pekerjaan mereka. Dalam pembelajaran tatap muka di kelas salah satu usaha untuk mendukung proses evaluasi diri adalah dengan adanya presentasi kelas. 
Presentasi kelas sangat berguna untuk melihat hasil kerja kelompok dari kelompok lain saat bekerja di kelas [17]. Sehingga mahasiswa dapat mengevaluasi jawaban dari setiap soal yang telah dikerjakan. Kemudian dalam pembelajaran online adanya proses evaluasi diri pada diri mahasiswa dapat didukung dengan adanya alat komunikasi yang digunakan untuk saling berinteraksi contohnya dengan menggunakan media pembelajaran moodle. Berikut ini adalah contoh kutipan dalam forum diskusi di Moodle yang mengindikasikan adanya evaluasi diri.

\section{M1 : "Lebar celah keluar dalam monokromator} menentukan panjang gelombang dari cahaya yang akan menyinari sampel. Maka dari itu, lebar celah keluar tersebut berpengaruh besar pada ketelitian dari spektrofotometer tersebut. Mengenai pentingnya lebar celah monokromator, lebar celah lebih kecil akan lebih baik daripada yang besar karena dapat meneruskan cahaya dengan panjang gelombang spesifik yang sesuai. Apabila digunakan celah yang lebih besar maka dikhawatirkan beberapa berkas sinar dengan panjang gelombang yang tidak diinginkan ikut keluar melalui celah monokromator dan mempengaruhi pengukuran absorbansi dn transmitan dari sampel".

M2 : "Menurut saya jawaban M1 tersebut kurang tepat karena celah sempit itu juga tidak baik. Mengapa? karena jika celahnya terlalu sempit maka cahaya monokromatik yang dikeluarkan akan mengalami difraksi atau pembelokan dari tepi celah. sehingga, cahaya monokromatik tersebut tidak dapat keluar secara sempurna atau dengan kata lain cahaya monokromatik yang keluar hanya sedikit. Jika seperti itu, maka nantinya akan dihasilkan nilai absorbansi dan transmitan yang tidak akurat. Terimakasih".

M3 : "Terima kasih atas sanggahan yang telah diberikan M2 sekaligus hal ini menjadi masukan untuk jawaban saya. Celah sempit akan mengakibatkan pembelokan dari tepi celah sehingga tidak cukup melewatkan energi untuk mengaktifkan detektor".

Berdasarkan hasil percakapan diatas, diketahui mahasiswa pertama memberikan jawaban kemudian mahasiswa kedua memberikan sanggahan atas jawaban tersebut sehingga mahasiswa pertama mengetahui letak kesalahan atas jawabannya. Percakapan ini menunjukkan adanya usaha evaluasi atau penilaian tugas oleh mahasiswa guna untuk mencapai tujuan suatu pemahaman yang benar.
Usaha evaluasi diri juga ditunjukkan ketika mahasiswa sedang melakukan percakapan dalam diskusi online atau mengerjakan kuis secara online, jika terdapat kata-kata yang kurang tepat mereka akan mengedit atau memperbaiki kata-kata yang telah diunggah. Hal ini dapat terlihat pada laporan aktivitas (report activity) pada moodle. Kembali membaca materi pelajaran atau hasil diskusi dapat membantu mahasiswa untuk mengecek beberapa hal yang mungkin dapat disertakan pada postingan diskusi atau jawaban kuis.

\section{Penataan lingkungan (Environmental structuring)}

Penataan lingkungan adalah proses regulasi diri yang mengindikasikan upaya peserta didik untuk mengatur lingkungan belajar agar membuat belajar lebih nyaman. Pembelajaran ini selain dilakukan tatap muka di kelas juga dilakukan pembelajaran secara online yang membutuhkan koneksi internet untuk menunjang keberlangsungan pembelajaran. Usaha yang dilakukan mahasiswa diantaranya dengan memanfaatkan fasilitas internet di kampus atau perpustakaan kampus untuk mencari koneksi internet yang cepat dan lancar. Namun tidak semua mahasiswa mengerjakan tugasnya di lingkungan kampus, ada juga yang lebih nyaman untuk mengerjakan di rumah. Mahasiswa dapat mengatur waktu dan tempat agar dapat mengerjakan tugas secara efisien.

\section{Mencari bantuan (Help seeking)}

Mencari bantuan merupakan usaha regulasi diri yang mengindikasikan untuk mencari bantuan dalam mengerjakan tugas atau mengenai materi pelajaran. Mahasiswa yang memiliki kemampuan dalam meregulasi diri sadar bahwa keterlibatan orang lain dalam pembelajaran mereka sangatlah penting [18]. Pembelajaran ini menggunakan struktur pembelajaran kooperatif STAD dimana mahasiswa dapat saling belajar bersama dan saling membantu sama lain. Berdasarkan observasi usaha dalam mencari bantuan yang dilakukan dalam kegiatan pembelajaran di kelas diantaranya adalah ketika diberikan bahan diskusi di kelas awalnya mahasiswa akan mengerjakan secara mandiri terlebih dahulu. Kemudian jika mengalami kesulitan mahasiswa akan bertanya pada mahasiswa lain yang lebih menguasai materi atau bertanya pada pengajar.

Dalam pembelajaran online, mahasiswa harus lebih proaktif dalam menggunakan teknologi, seperti email, forum diskusi, chat seperti halnya dalam pertemuan tatap muka [18]. Dengan menggunakan media moodle mahasiswa dapat saling berkomunikasi dengan kelompoknya saat diluar jam pelajaran, saling berdiskusi dan tukar informasi dari sumber referensi guna menambah pengetahuan. Sejalan dengan penelitian yang telah dilakukan oleh Dabbagh \& Kitsantas, salah satu mahasiswanya mengatakan bahwa area diskusi sangat membantu dalam mencari 
perspektif dari yang lain, area diskusi memfasilitasi kolaborasi, diskusi pada forum diskusi dapat terekam dengan baik sehingga mahasiswa mudah dalam memberikan komentar dan membaca hasil diskusi [14].

\section{Berpikir kritis (Critical thinking)}

Indikator berpikir kritis pada penelitian ini menghasilkan skor rata-rata yang tinggi yaitu pada mahasiswa dengan SRL tinggi $(12,00)$ dan skor ratarata cukup pada mahasiswa dengan SRL rendah $(9,88)$. Hal ini menunjukkan bahwa sebagian besar mahasiswa sudah menggunakan strategi kognitif berpikir kritis dengan usahanya masing-masing.

Usaha mahasiswa dalam menggunakan strategi berpikir kritis seperti dapat memberikan penjelasan terhadap suatu istilah, dapat memikirkan alternatif-alternatif yang mungkin dilakukan utuk mengatasi masalah menyebutkan contoh dan dapat mengemukakan alasan yang berhubungan dengan masalah yang diberikan atau pertanyaan tentang suatu masalah atau kasus. Berikut contoh hasil jawaban mahasiswa yang menunjukkan penggunaan berpikir kritis.

M : “Larutan blanko merupakan larutan yang tidak berisi analit. Larutan blanko biasanya digunakan untuk tujuan kalibrasi sebagai larutan pembanding dalam analisis fotometri. Jadi tidak selalu blanko berisi air. Sebagai contoh: pada praktikum $x$ untuk menguji absorbansi analit digunakan asam untuk menurunkan pH agar analit keluar (praktikum biokim serat pisang), maka perlakuan pada larutan blanko sama namun tanpa analit, hakikatnya agar yang menjadi fokus pengukuran absorbansi hanya analit”.

Mahasiswa tersebut menunjukkan indikator berpikir kritis dalam memberikan jawaban yang disertai dengan penjelasan berupa pemberian contoh yang termasuk dalam suatu konsep yang diberikan. Kemudian pada pembahasan alat instrumentasi spektrofotometer UV-VIS diberikan dua video tentang spektrofotometer berkas tunggal dan berkas ganda, mahasiswa dapat menjelaskan mekanisme dan perbedaan dari kedua spektrofotometer tersebut seperti pada percakapan berikut ini.

M1 : Berdasarkan video tersebut dapat diketahui bahwa spektrofotometer dengan berkas sinar ganda, blanko dan larutan sampel dapat diukur secara bersama-sama dalam satu kali proses pengukuran, dan langsung dapat tergambar melalui detektor. Sehingga, prosesnya dapat berjalan dengan efektif dan efisien. Pada alat ini, terdapat chopper yang berfungsi untuk membagi sinar menjadi dua bagian, satu bagian sinar melewati blanko dan sinar yang satunya melewati larutan sampel.

M2 : Sedangkan pada spektrofotometer dengan berkas sinar tunggal, cahaya hanya melewati satu arah sehingga nilai yang diperoleh hanyalah nilai absorbansi dari larutan yang dimasukan. Sehingga, pengukurannya harus bergantian antara pengukuran larutan sampel dengan pengukuran blanko. Pengukurannya juga harus dilakukan berulang-ulang agar dapat diperoleh suatu data yang dapat dibaca dan digambar grafiknya pada detektor.

Selain dalam diskusi online mengenai materi alat instrumentasi spektrometer atom, indikator berpikir kritis diketahui ketika mahasiswa dapat menjelaskan arti atau makna dari suatu pernyataan dengan menggunakan kalimatnya sendiri seperti pada contoh percakapan berikut ini.

M3 : Saya ingin bertanya tentang Pelebaran Doppler, doppler itu apa? apa efek yang ditimbulkan dalam sebuah analisis apabila terjadi pelebaran Doppler?

M4 : Doppler merupakan penemu dari efek Doppler yaitu Christian Doppler. Efek Doppler terjadi karena adanya gerakan atom terhadapa suatu sumber cahaya, frekuensinya menjadi lebih tinggi dan panjang gelombang lebih pendek atau sebaliknya. Makin tinggi temperatur, gerak atom makin cepat. Akibat efek Doppler yaitu setiap atom akan menyerap foton dengan panjang gelombang yang berbeda, bergantung kecepatan radiasi terhadap pengamat. Hal ini berakibat pelebaran pada garis spectrum

\section{Elaborasi (Elaboration)}

Indikator elaborasi sudah tercapai dengan skor rata-rata yang tinggi pada mahasiswa dengan SRL tinggi $(10,11)$ dan cukup pada mahasiswa dengan SRL rendah $(8,38)$. Elaborasi sebagai usaha regulasi diri dalam belajar membantu mahasiswa menempatkan informasi dalam long term memorynya dengan cara membangun hubungan internal diantara hal-hal yang dipelajari. Usaha elaborasi yang digunakan oleh mahasiswa dalam pembelajaran ini meliputi dapat membuat ringkasan dari hasil diskusi atau membuat ringkasan materi dengan menggunakan 
kalimat sendiri, membuat suatu analogi atau ide dan membuat catatan umum dari semua informasi yang didapat baik pada referensi dari internet maupun dari buku-buku.

\section{KESIMPULAN}

Berdasarkan hasil penelitian, dapat disimpulkan bahwa mahasiswa yang memiliki self regulated learning tinggi lebih banyak daripada mahasiswa yang memiliki self regulated learning rendah. Aspek manajemen waktu pada kedua kelompok memiliki skor rata-rata yang tinggi dan indikator pencarian bantuan (help seeking) pada kedua kelompok memiliki skor rata-rata paling rendah.

\section{DAFTAR PUSTAKA}

[1] Wolters, C.A. 1998. Self-Regulated Learning and College Students' Regulation of Motivation. Journal of Educational Psychology, 90 (2): 224-235.

[2] Schunk, D.H., Pintrich, P.R., \& Meece, J.L. 2012. Motivasi dalam Pendidikan: Teori, Penelitian, dan Aplikasi Edisi Ketiga. Jakarta: PT Indeks.

[3] Wolters, C.A., Pintrich, P.R., \& Karabenick, S.A. 2003. Assessing self-regulated learning. Diseminarkan pada Conference on Indicators of Positive Development: Definitions, Measures, and Prospective Validity. Sponsored by ChildTrends, National Institutes of Health. Maret 2003.

[4] Azizah, N. (2016). Pengembangan LKS Dan Penerapannya Dalam Pembelajaran Kooperatif Tipe STAD Untuk Meningkatkan Aktivitas Dan Hasil Belajar Kimia Siswa. Jurnal Pijar Mipa, 11(1).

[5] Wijayanti, A. (2016). Implementasi model pembelajaran kooperatif tipe TGT sebagai upaya meningkatkan pemahaman konsep Fisika Dasar mahasiswa pendidikan IPA. Jurnal Pijar Mipa, 11(1).

[6] Bayuaji, P., Hikmawati, H., \& Rahayu, S. (2017). Pengaruh Model Pembelajaran Kooperatif Tipe Student Facilitator And Explaining (Sfae) Dengan Pendekatan Saintifik Terhadap Hasil Belajar Fisika. JURNAL PIJAR MIPA, 12(1).

[7] Greene, J.A. \& Azevedo, R. 2009. A macrolevel analysis of SRL processes and their relations to the acquisition of a sophisticated mental model of a complex system. Contemporary Educational Psychology, 34 (1): 18-29.

[8] Cho, M.H. \& Shen, D. 2013. Self Regulated in Online Learning. Distance Education, 34 (3): 290-301.

[9] Jonassen, D., Davidson, M., Collins, M., Campbell, J., and Haag, B.B. 1995. Constructivism and computer-mediated communication in distance education. The American Journal of Distance Education, 9 (2): 7-26.

[10] Fraenkel, J.R. \& Wallen, N.E. 2009. How to design and evaluate research in education 7 th Edition. New York: McGraw-Hill Companies.

[11] Trisnawati, A, in Prosiding Seminar Nasional II Tahun 2016 Kerjasama Prodi Pendidikan Biologi FKIP dengan Pusat Studi Lingkungan dan Kependudukan (PSLK) Universitas Muhammadiyah Malang. ed. R. Abdulkadir, Malang, Indonesia, 2016, 355-368.

[12] Barnard, L., Lan, W.Y., To, Y.M., \& Paton, V.O. 2008. Measuring self-regulation in online and blended learning environments. Internet and Higher Education, 12 (2009): 1-6.

[13] Orhan. 2007. Applying Self Regulated Learning Strategis in a Blended Learning Instruction. World Applied Science Journal, 2 (4): 290-398.

[14] Tsai, C., Shen, P., \& Tsai, M. 2011. Developing An Appropriate Design Of Blended Learning with Web-Enabled SelfRegulated Learning to Enhance Students' Learning and Thoughts Regarding Online Learning. Behaviour \& Information Technology, 30 (2): 261-271.

[15] Zimmerman, B.J. 1989. A Social cognitive view of self regulated learning. Journal of Educational Psychology, 81 (3): 329-339.

[16] Whipp, J.L. \& Chiarelli, S. 2004. SelfRegulation in a Web-Based Course: A Case Study. ETR\&D, 52 (4): 5-22.

[17] Dabbagh, N. \& Kitsantas, A. 2005. Using web-based pedagogical tools as scaffolds for self-regulated learning. Instructional Science, 33: 513-540.

[18] Lynch, R. \& Dembo, M. 2004. The Relationship between Self-Regulated and Online Learning in a Blended Learning Context. International Review of Research in Open and Distance Learning, 5 (2): 1-16. 